\title{
Genetic Immunization with CDR3-Based Fusion Vaccine Confers Protection and Long-Term Tumor-Free Survival in a Mouse Model of Lymphoma
}

\author{
Sandra Iurescia, ${ }^{1}$ Daniela Fioretti, ${ }^{1}$ Pasquale Pierimarchi, ${ }^{1}$ Emanuela Signori, ${ }^{1,2}$ \\ Manuela Zonfrillo, ${ }^{1}$ Giancarlo Tonon, ${ }^{3}$ Vito M. Fazio, ${ }^{2}$ and Monica Rinaldi ${ }^{1}$ \\ ${ }^{1}$ Institute of Neurobiology and Molecular Medicine, Department of Medicine, National Research Council (CNR), \\ Via Fosso del Cavaliere 100, 00133 Rome, Italy \\ ${ }^{2}$ CIR, Section of Molecular Medicine and Biotechnology, University “Campus Bio-Medico”, Via Álvaro del Portillo 21, \\ 00128 Rome, Italy \\ ${ }^{3}$ Bio-Ker, Scientific Park “Polaris”, Località Piscinamanna, 09010 Pula (Cagliari), Italy
}

Correspondence should be addressed to Monica Rinaldi, monica.rinaldi@artov.inmm.cnr.it

Received 9 November 2009; Accepted 4 February 2010

Academic Editor: Daila S. Gridley

Copyright (๑) 2010 Sandra Iurescia et al. This is an open access article distributed under the Creative Commons Attribution License, which permits unrestricted use, distribution, and reproduction in any medium, provided the original work is properly cited.

Therapeutic vaccination against idiotype is a promising strategy for immunotherapy of B-cell malignancies. We have previously shown that CDR3-based DNA immunization can induce immune response against lymphoma and explored this strategy to provide protection in a murine B-cell lymphoma model. Here we performed vaccination employing as immunogen a naked DNA fusion product. The DNA vaccine was generated following fusion of a sequence derived from tetanus toxin fragment $\mathrm{C}$ to the $\mathrm{V}_{\mathrm{H}} \mathrm{CDR} 3_{109-116}$ epitope. Induction of tumor-specific immunity as well as ability to inhibit growth of the aggressive 38C13 lymphoma and to prolong survival of vaccinated mice has been tested. We determined that DNA fusion vaccine induced immune response, elicited a strong protective antitumor immunity, and ensured almost complete long-term tumor-free survival of vaccinated mice. Our results show that CDR3-based DNA fusion vaccines hold promise for vaccination against lymphoma.

\section{Introduction}

Lymphomas represent the fifth most common malignancies. Each year, approximately 55000 new cases are diagnosed with non-Hodgkin's lymphomas (NHLs) in the United States [1]. Despite current therapeutic strategies including chemotherapy, transplantation, and passive immunotherapy with monoclonal antibodies, many lymphoma patients remain incurable. The recent years have witnessed the development of a variety of promising immunotherapies for treating patients with B-cell NHLs. Vaccine strategies targeting NHLs have largely focused on using the idiotype (Id) of the tumor immunoglobulin (Ig) individually expressed on the surface of malignant B cells as tumorspecific antigen $(\mathrm{Ag})$. After decades of work, some clear evidence of clinical efficacy in phase I/II trials using Id protein vaccines has accumulated, despite results from phase
III trials seem disappointing [2, 3]. Furthermore, streamlined production of these patient-specific vaccines is required for eventual clinical application.

Several strategies are being developed to improve these results and include optimization of antigen delivery and presentation as well as enhancement of antitumor $\mathrm{T}$ cell function.

DNA vaccines have emerged as a novel lymphoma vaccine formulation for antigen-specific immunotherapy [4]. Such a method is an attractive and effective approach for active therapeutic vaccination since it does not require the production and isolation of a purified protein for each patient, a process that is expensive, laborious, and time-consuming. The protein is endogenously produced and secreted, which may result in more efficient antigen presentation in both classes I and II major histocompatibility complex (MHC) pathways resulting in enhanced anti-Id 
immune responses. In addition to their safety, stability, ease of production, DNA vaccines are highly flexible, allowing coexpression of several types of antigens and immunological proteins [5]. Furthermore, the performance of DNA vaccines may be improved by in vivo electroporation (EP) as a safe and efficient method of in vivo delivery resulting in greatly enhanced DNA uptake, protein expression levels, and degree of local inflammation [6]. DNA vaccination has been applied to therapy of experimental murine lymphomas (for reviews, see Hurvitz and Timmerman [7] and Neelapu et al. [8]). DNA vaccines that express either the tumor-derived Id or the tumor variable $(\mathrm{V})$ regions in a single-chain $\mathrm{Fv}$ conformation $(\mathrm{scFv})$ have been constructed. However, due to the weak immunogenicity in most cases, their effectiveness depend on carrier proteins or adjuvant proteins linked to the Id structures [9-14].

Idiotypic antigenic determinants lying mainly within the complementary-determining regions (CDRs) 3 have been considered a "hot spot" of particular interest for construction of subunit vaccines [15-18]. Vaccines including only this minimal antigenic domain were proved to induce antibody response $[19,20]$.

We demonstrated that DNA immunization of outbred mice with different patient-derived $\mathrm{V}_{\mathrm{H}} \mathrm{CDR} 3$ peptides elicited antibodies able to recognize native antigens on individual patient's tumor cells [20]. Recently, our group has shown the tumor protective effects recruited by CDR3-based DNA vaccines in a poorly immunogenic, highly aggressive murine B-cell lymphoma model. A DNA vaccine containing a $\mathrm{V}_{\mathrm{H}} \mathrm{CDR} 3$ epitope of the 38C13 B-cell lymphoma [21], administered in combination with the $\mathrm{V}_{\mathrm{L}} \mathrm{CDR} 3$-encoding plasmid, provided tumor protection and long-term tumorfree survival in $60 \%$ of syngeneic mice [22]. In the current study to enhance the potency of this vaccination platform, we used the DNA fusion vaccine design encoding tumor Ags linked to pathogen-derived sequences, aimed to provide $\mathrm{CD}^{+} \mathrm{T}$ cell help. Engagement of $\mathrm{CD}^{+} \mathrm{T}$ helper $\left(\mathrm{T}_{\mathrm{H}}\right)$ cells has been shown to play a major role in linking and coordinating innate and adaptive immune responses $[4,23]$. Many attempts to incorporate exogenous helper antigens into DNA vaccine design to break tolerance to self (tumor) antigens and to improve efficacy by helper $\mathrm{T}$ cells have been described [24-28]. Fusion protein of tetanus toxin fragment C (TTFrC) first domain to human CEAderived peptide provided activating signals required for DNA vaccines against weak Ags [25].

Based on such finding, we generated a DNA vaccine consisting of a fusion between a sequence belonging to TTFrC and the $\mathrm{V}_{\mathrm{H}} \mathrm{CDR}_{109-116}$ epitope already described [22]. Here we present data on the antitumor efficacy of the CDR3-based DNA fusion vaccine delivered by intramuscular electroporation in a B-cell lymphoma model.

\section{Materials and Methods}

2.1. Cell Lines. 38C13, a carcinogen-induced B-cell lymphoma in the $\mathrm{C} 3 \mathrm{H} / \mathrm{HeN}$ murine strain, expresses an IgM/ $/ \kappa$ surface antigen, is MHC $\mathrm{II}^{-}$[21], and was cultured in
RPMI 1640, 10\% heat-inactivated FBS, $2 \mathrm{mM}$ L-glutamine, $100 \mathrm{U} / \mathrm{mL}$ penicillin, $100 \mathrm{U} / \mathrm{mL}$ streptomycin, and $50 \mu \mathrm{M} \beta$ Mercaptoethanol. This culture medium is referred to as the complete medium throughout this study. $38 \mathrm{C} 13$ cell line was used for tumor challenge experiments.

2.2. Construction of DNA Vaccines. Tetanus toxin (TT) fragment-encoding DNA was amplified by PCR from chromosomal DNA of recombinant Streptococcus gordonii strain GP1253 (kindly provided by Dr. Pozzi, University of Siena, Italy) [29]. The primers (forward 5'-CCG CTC GAG TCA ACA CCA ATT CCA TTT TC-3' and reverse 5'-CCC AAG CTT TGT CCA TCC TTC ATC TGT-3'), containing the restriction sites XhoI and HindIII (in bold), respectively, were designed to amplify the sequence coding for amino acids 856-1313 of tetanus toxin gene (GenBank Accession No. $\mathrm{X} 04436)$. The TT fragment spans from aa 856 to aa 1313 (Hchain) and included 9 amino acids of fragment B (aa 856864).

The amplified fragment was inserted in the cloning vector pUC19, and the resulting recombinant plasmid was named $\mathrm{pUC}-\mathrm{TT}_{856-1313}$. Sequencing of the cloned TT fragment revealed three-point mutations (already present in the TT-expressing recombinant $S$. gordonii strain), which lead to three amino acids substitutions in the protein sequence: N919D, N998D, and M1240V.

The plasmid pUC-TT ${ }_{856-1313}$ was used as template for the amplification of the partial TT fragment sequence $\left(\mathrm{TT}_{933-1126}\right)$. The fusion vaccines $\mathrm{pTT}_{933-1126}-\mathrm{V}_{\mathrm{H}} \mathrm{CDR} 3$ and $\mathrm{pTT}_{933-1126}-\mathrm{V}_{\mathrm{L}} \mathrm{CDR} 3$ were assembled by PCR amplification using the $\mathrm{TT}_{933}$ forward primer $\left(5^{\prime}\right.$-CTA GCT AGC GCC ACC ATG GTT ATA GTG CAT AAA- $3^{\prime}$,NheI site underlined) in combination with either the $\mathrm{TT}_{1126} \mathrm{~V}_{\mathrm{H}} \mathrm{CDR} 3$ reverse primer (5'-ATAGTTTAGCGGCCGCTTAAATGTAGTCAAAGTACCCTTCGTATGTATCATATCGTAAAG-3' ${ }^{\prime}$,Not I site underlined) or the $\mathrm{TT}_{1126} \mathrm{~V}_{L} \mathrm{CDR} 3$ reverse primer (5' -ATAGTTTAGCGGCCGCTTATCCAAACGTGTACAGATTATCATACTGTAGACATGTATCATATCGTAAAG$3^{\prime}$,NotI site underlined). The $\mathrm{V}_{\mathrm{H}}$ CDR3 sequence specifies the 8-mer $\mathrm{H}-2 \mathrm{~K}^{\mathrm{K}}$ "anchor modified" YEGYFDYI ${ }_{109-116}$ epitope of the murine B-cell lymphoma 38C13 Id, while the $V_{L}$ sequence expressed the 11-mer peptide starting with the Cysteine88 (i.e., Cys104 in the IMGT unique numbering [30]) and encompassing the CDR3 and the conserved Phenylalanine and Glycine residues of framework (FR)4 [22]. The reverse primer overlapped the $\mathrm{TT}_{933-1126}$ carboxyl region and contained an overhang encoding the 38C13 Id peptides, fusing it to $\mathrm{TT}_{933-1126} \mathrm{C}$ terminus. A DNA fragment encoding the $\mathrm{TT}_{933-1126}$ sequence alone was also obtained by means of the $\mathrm{TT}_{933}$ forward primer together with TT $_{1126}$ reverse primer $\left(5^{\prime}\right.$-ATAGTTTAGCGGCCGCTTATGTATCATATCGTAAAG-3',NotI site underlined). The $\mathrm{TT}_{933}$ forward primer also encoded the Kozak consensus sequence and an ATG start codon.

The expression plasmid pRC110-NTS-IL-2 [22] was used as recipient for cloning of the recombinant fragments under the RSV promoter. The resulting PCR products were ligated into pRC110-NTS-IL-2 as NheI-NotI fragments. 
All constructs were sequenced, and plasmid DNA was purified for vaccination using a QIAfilter Giga Kit Endotoxin-free (Qiagen S.p.A., Italy).

2.3. Mice, DNA Vaccination, and Tumor Challenge Protocols. Male $\mathrm{C} 3 \mathrm{H} / \mathrm{HeN}\left(\mathrm{H}-2 \mathrm{~K}^{K}\right)$ mice, 8- to 9-week old, were obtained from Charles River Italia S.p.A. (Calco, Italy) and maintained in the Animal Facility at the "Sacro Cuore" Catholic University of Rome, Italy. All animal experiments, including anaesthetic procedures, were conducted in accordance with protocols approved by the Italian Ministry of Health. For protective experiments, on day 0 anesthetized mice (ketamine-Domitor mixture; pTTV $\mathrm{H}_{\mathrm{H}} \mathrm{CDR} 3$ group, $n=$ 7; pTT group, $n=6$ ) were vaccinated with a total of $50 \mu \mathrm{g}$ DNA plasmid in $150 \mathrm{mM}$ phosphate saline buffer into two sites of posterior muscle legs and received booster injection 3 weeks later. Both vaccinations were followed by electroporation with BTX ECM 830 Pulse Generator (Harvard Apparatus, MA, USA) at $175 \mathrm{~V} / \mathrm{cm}, 10 \mathrm{~ms}$ squarewave pulses, $1 \mathrm{~Hz}$. Muscles were pretreated with bovine hyaluronidase as reported elsewhere [31]. Unimmunized (naïve) mice $(n=6)$ received a mock vaccination by injection with phosphate saline buffer. Serum samples were collected by tail bleeding 3 weeks after priming and 2 weeks after boosting injections. All groups were challenged 2 weeks after the booster vaccination by intraperitoneal injection of $2 \times$ $10^{2} 38 \mathrm{C} 13$ tumor cells.

In the therapeutic setting, on day $0 \mathrm{C} 3 \mathrm{H} / \mathrm{HeN}$ mice were challenged i.p. with a lethal dose of $38 \mathrm{C} 13\left(2 \times 10^{2}\right)$ tumor cells. DNA electrotransfer was performed 4 days after challenge and repeated 11 days later, with a total of $80 \mu \mathrm{g}$ DNA plasmids pTTV $\mathrm{H}_{\mathrm{H}} \mathrm{CDR} 3 / \mathrm{pTTV} \mathrm{V}_{\mathrm{L}} \mathrm{CDR} 3$ or with $50 \mu \mathrm{g}$ of pTT (6 mice/experimental group). Unimmunized mice ( $n=$ 5) received a mock vaccination. EP settings were the same used in the prophylactic experiments.

Clinical evidence of tumor and mouse survival were monitored and compared between groups. Animals were checked for visible abdominal tumors and tumor development was monitored daily by abdominal palpation. Animals were checked daily thereafter for mortality.

2.4. Peptide Synthesis. The native peptides $\mathrm{NH}_{2}$-DPNYYDGSYEGYFDYWAQGTTL-COOH (IgM 38C13V $\left.\mathrm{V}_{\mathrm{H} 101-122}\right)$ and $\mathrm{NH}_{2}$-MHTAVYYCAKGAQGASLGKAYFFDCWGQGTQVTVSS-COOH ( $\mathrm{V}_{\mathrm{H}} \mathrm{CDR} 3-\mathrm{PA}$; [20]) were synthesized by Primm (Primm S.r.l., Italy) and dissolved in the suggested buffer prior to use.

2.5. Anti-Idiotype Antibody Detection by ELISA. ELISA plates were coated with $50 \mu \mathrm{g} / \mathrm{mL}$ of $\mathrm{V}_{\mathrm{H} 101-122}$ peptide or $\mathrm{V}_{\mathrm{H}}$ CDR3-PA as irrelevant peptide and incubated o.n. at $4^{\circ} \mathrm{C}$. Plates were quenched at r.t. for 2 hours with $3 \%$ BSA. Mice sera, diluted 1 : 100 in PBS 1X/0,1\% BSA/0,05\% Tween 20, were added and incubated for 2 hours at r.t. Reactive antibodies were detected with sheep antimouse IgG HRP-conjugated (1 : 5000 diluted, Amersham Biosciences, Italy). Plates were then developed by adding ABTS substrate (Sigma-Aldrich S.r.l., Italy). Absorbance was read at
$405 \mathrm{~nm}$ using ELISA microplate reader. All measurements of antibody levels in individual animals were determined in triplicate.

2.6. Ex Vivo Intracellular IFN- $\gamma$ Assay. Mice (3 animals/experimental group) were culled 1 week after booster DNA injection and spleens were removed. Spleens were perfused with $10 \mathrm{~mL}$ RPMI 1640 culture medium, cell suspension were passed through $100 \mu \mathrm{m}$ nylon cell strainer (BD Falcon, BD Biosciences Europe, Belgium) to remove large cells aggregates, and then centrifuged at $1,000 \mathrm{rpm}$ for 10 minutes. Cells were resuspended in $1 \mathrm{~mL}$ medium, counted, centrifuged a second time and then resuspended in 90\% FBS/10\%DMSO and cryopreserved until assessment.

To assess priming of $\mathrm{CD}^{+} \mathrm{T}$ cells, splenocytes harvested from groups of immunized mice were processed for detection on intracellular IFN- $\gamma$. Cells $\left(2 \times 10^{6} /\right.$ well $)$ were incubated for 5 hours at $37^{\circ} \mathrm{C}$ in 24 -well plates in $2 \mathrm{~mL}$ complete medium supplemented with $2 \mathrm{mM}$ sodium pyruvate, $1 \%$ nonessential amino acids ( $1 \%$ of $100 \mathrm{x}$ stock). Splenocytes were stimulated with $100 \mu \mathrm{g} / \mathrm{mL} \mathrm{V}_{\mathrm{H} 101-122}$ in the presence of $1 \mu \mathrm{L} / \mathrm{mL}$ cell culture of Golgi Plug (BD Biosciences Europe, Belgium). Following incubation, stimulated cells were washed twice and Fc receptors were blocked by incubation with rat antimouse CD16/CD32 (Fc Block; BD Biosciences Pharmingen, CA, USA) for 30 minutes. Samples were processed to label surface CD8 (PerCP antimouse CD8a-clone 53-6.7) and subsequently fixed and permeabilized. Cells were stained with Alexa Fluor 488 antimouse IFN- $\gamma$ (clone XMG1.2) for intracellular labelling and analyzed by FACSCalibur using Cell Quest Pro software (BD, CA, USA). Data collection was gated on live spleen lymphocytes by forward and side angle scatter, utilised to exclude dead cells, debris, nonlymphoid cell, and cell aggregates. Values indicated in the FACS plots refer to double positive cells $\left(\mathrm{CD}^{+}\right.$IFN- $\left.\gamma^{+}\right)$as percentage of total lymphocytes population. Statistical markers were set using unlabelled cells as reference. Typically, less then $0.08 \%$ positive cells were detected beyond the statistical marker in the above negative controls. Fluorochromes-conjugated Abs were purchased from Biolegend, CA, USA.

2.7. Statistical Analysis. Data from ELISA assay were analysed by unpaired, two-tailed $t$-test. Survival analyses were performed using the Kaplan-Meier method and the log-rank test. Tumor-bearing animal proportions and intracellular cytokine staining proportions were compared by $X^{2}$ analysis (MedCalc Software, Mariakerke, Belgium).

\section{Results}

3.1. DNA Vaccines and Experimental Design. In this study a DNA fusion vaccine containing pathogen-derived sequence as an immunoenhancer element was generated. The $\mathrm{H}-2 \mathrm{~K}^{K}$ MHC class I binding motif-guided "Epitope prediction" (SYFPEITHI database, http://www.syfpeithi.de [32]) was applied to a TT fragment that spans from aa 856 to aa 1313 (GenBank Acc. no. X04436). An amino acids region was 


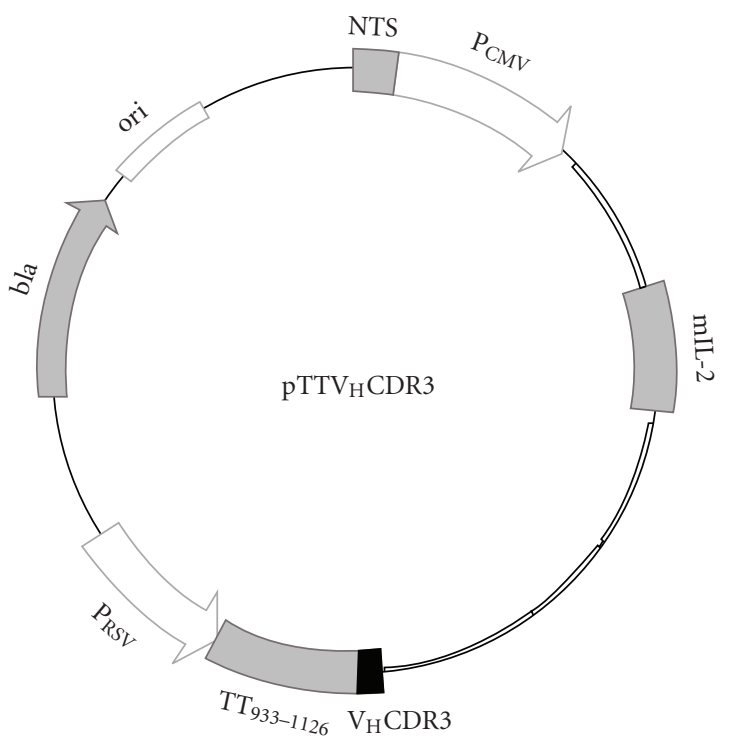

(a)

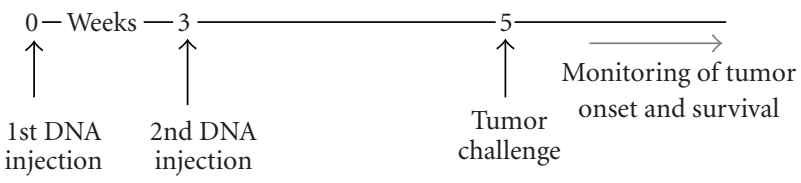

(b)

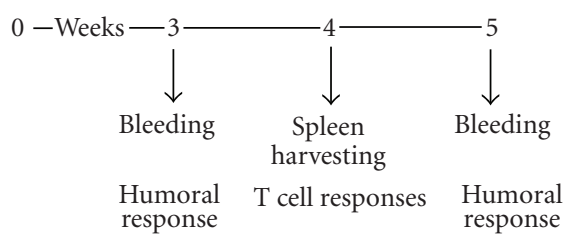

(c)

FIGURE 1: DNA fusion vaccine schematic structure (a). Experimental design of protective (b) and immune responses (c) studies is showed. $\mathrm{C} 3 \mathrm{H} / \mathrm{HeN}$ mice were immunized twice at 3 -week intervals by intramuscular injection followed by electroporation. Unimmunized (naïve) mice received a mock vaccination by injection with phosphate saline buffer. Two weeks after boosting mice were injected i.p. with $2 \times 10^{2} 38 \mathrm{C} 13$ cells.

selected (TTFrC933-1126) which overlaps some of $\mathrm{CD}^{+}{ }^{+} \mathrm{T}$ cell epitopes (the $\mathrm{TT}_{947-967}$ epitope, the $\mathrm{TT}_{1084-1099}$ epitope, $\mathrm{TT}_{1058-1077}$ epitope) present on the microbial toxin sequence [33-35]. Furthermore, this TTFrC portion should lack of potentially competing epitopes as regards $\mathrm{V}_{\mathrm{H}} \mathrm{CDR} 3_{109-116}$ epitope, avoiding phenomenon of immunodominance [36].

To construct the DNA vaccine, the amplified fragment $\mathrm{TT}_{933-1126} \mathrm{~V}_{\mathrm{H}} \mathrm{CDR} 3_{109-116}$ was generated after PCR reactions, as described in Section 2. This fragment was cloned into pRC110-NTS backbone vector [22], and the recombinant plasmid designed as $\mathrm{pTTV}_{\mathrm{H}} \mathrm{CDR} 3$, as reported in Figure 1(a). Additionally our plasmid encodes murine IL2 as cytokine adjuvant. Likewise, the recombinant plasmid pTTV $_{\mathrm{L}}$ CDR3 was obtained by cloning the amplified
TABLE 1: Reactivity of mouse sera against a CDR3 control (irrelevant) peptide as assessed by ELISA.

\begin{tabular}{|c|c|c|}
\hline Mice groups Vaccine formulation & Absorbance $(\mathrm{nm})^{1}$ & $P^{2} \mathrm{~A}$ versus $\mathrm{B}$ \\
\hline $\mathrm{pTTV}_{\mathrm{H}} \mathrm{CDR} 3$ & $0.159 \pm 0.161$ & NS \\
\hline pTT & $0.049 \pm 0.208$ & \\
\hline
\end{tabular}

fragment $\mathrm{TT}_{933-1126} \mathrm{~V}_{\mathrm{L}} \mathrm{CDR} 3_{88-98}$ in the same backbone vector. A plasmid encoding the $\mathrm{TT}_{933-1126}$ sequence alone in the same backbone vector was also obtained and named pTT.

Plasmid DNA vaccination was performed using the RSV promoter driving $\mathrm{TT}_{933-1126} \mathrm{~V}_{\mathrm{H}} \mathrm{CDR} 3_{109-116}$ expression plasmid (pTTV $\mathrm{H}_{\mathrm{H}} \mathrm{CDR} 3$ ), while pTT was used as control vaccine. Naïve mice received a mock vaccination by injection with phosphate saline buffer. Our DNA vaccination protocol consists of two DNA injections both associated with electroporation [22]. Experimental design of protective and immunological studies is showed in Figures 1(b) and 1(c), respectively.

3.2. Antibody Response Analysis. The levels of antibody response specific to DNA fusion vaccine were evaluated in mice following intramuscular immunization. Humoral immune response elicited after pTTV $_{\mathrm{H}} \mathrm{CDR} 3$ or pTT immunizations was assayed by ELISA for $\mathrm{V}_{\mathrm{H}}$ peptide $\left(\mathrm{D}_{101}-\mathrm{L}_{122}\right)$ reactive antibodies.

We wondered whether the immunization regimen might influence the immune outcome. Individual blood samples were collected from mice ( $\mathrm{pTTV}_{\mathrm{H}} \mathrm{CDR} 3$ group, $n=7$; control groups, $n=6) 3$ weeks after DNA priming and 2 weeks after boosting injections. The response profile for each vaccine group has been depicted in Figure 2. ELISA test failed to detect antibody titers when performed with mice sera collected after priming as well as analyses of individual sera within the $\mathrm{pTTV}_{\mathrm{H}} \mathrm{CDR} 3$ group revealed no noticeable differences compared to unimmunized and pTT control groups (Figure 2(a)).

Two weeks after boosting, mice immunized with pTTV $_{\mathrm{H}}$ CDR3 DNA vaccine showed sera positive for antibodies directed against the $\mathrm{V}_{\mathrm{H}}$ peptide $\left(\mathrm{D}_{101}-\mathrm{L}_{122}\right)$ (Figure 2(b)). Compared with pTT control vaccine and unimmunized groups, the pTTV $\mathrm{H}_{\mathrm{H}} \mathrm{CDR} 3$ vaccine group antibody level was statistically significant $(P=.0045$ and $P=.0014$, resp.).

The lack of antibody response after priming suggests that boosting is critical for antibody induction. Our data essentially confirmed that immunization schedule was critical for this Ag system [37].

Reactivity of mouse sera against a CDR3 irrelevant peptide $\left(\mathrm{V}_{\mathrm{H}} \mathrm{CDR} 3-\mathrm{PA}[22]\right)$ generated no significant response (Table 1).

3.3. Induction of IFN- $\gamma$ Producing $C D 8^{+} T$ Cells by Fusion DNA Vaccine. To investigate whether our vaccination strategy could induce positive $\mathrm{CD}^{+} \mathrm{T}$ cell responses to $\mathrm{V}_{\mathrm{H}} \mathrm{CDR} 3$ 


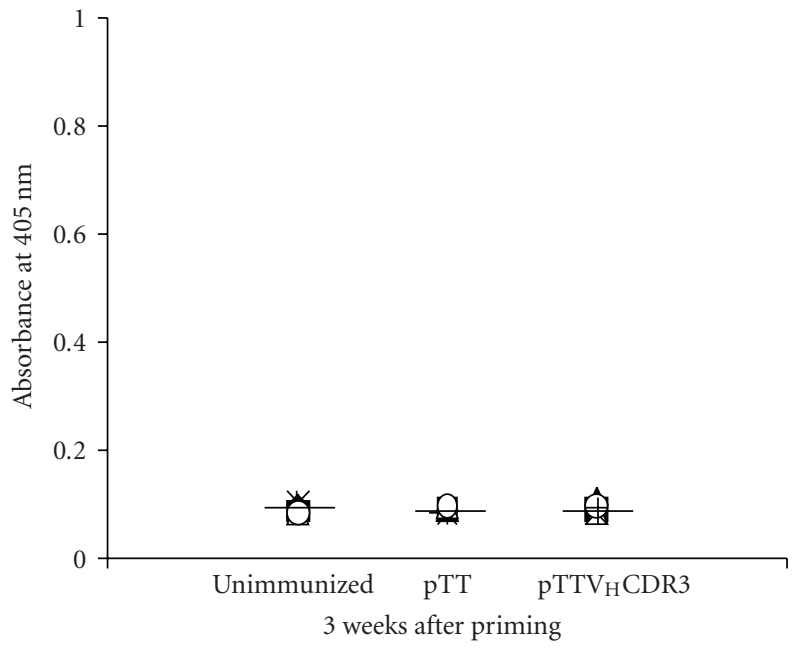

(a)

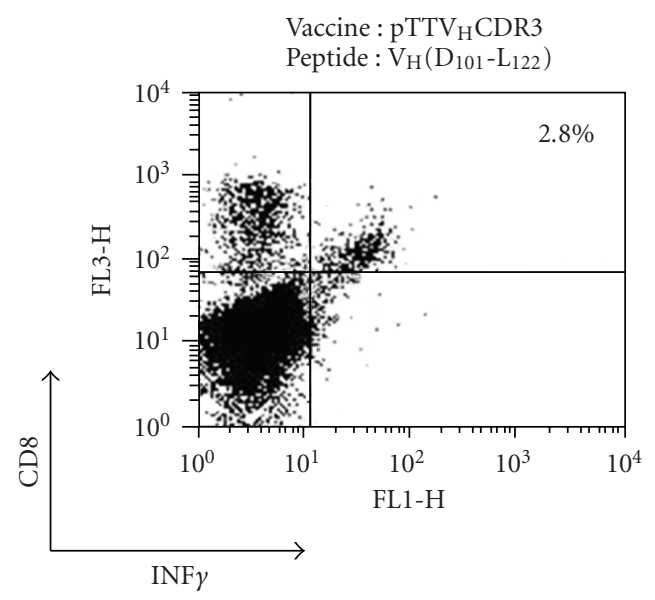

(c)

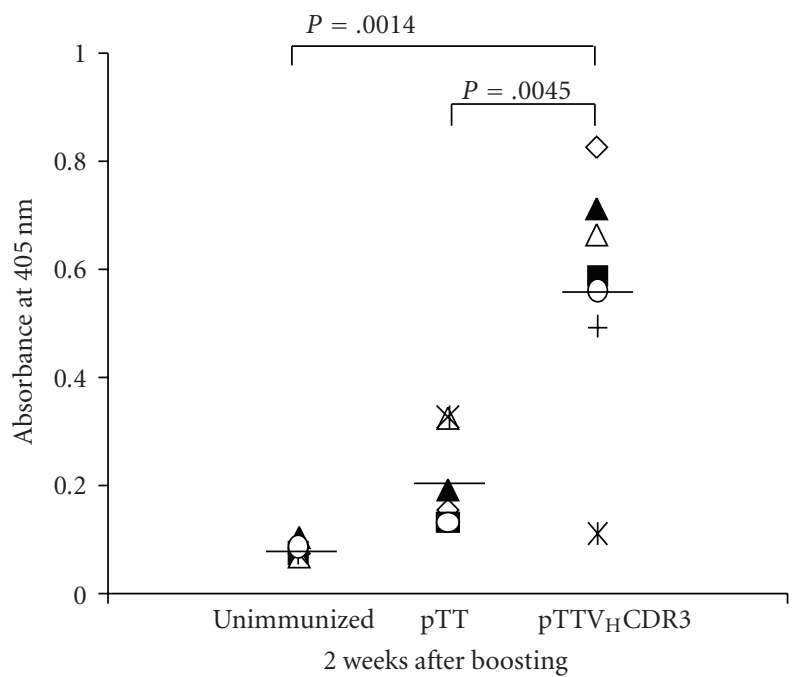

(b)
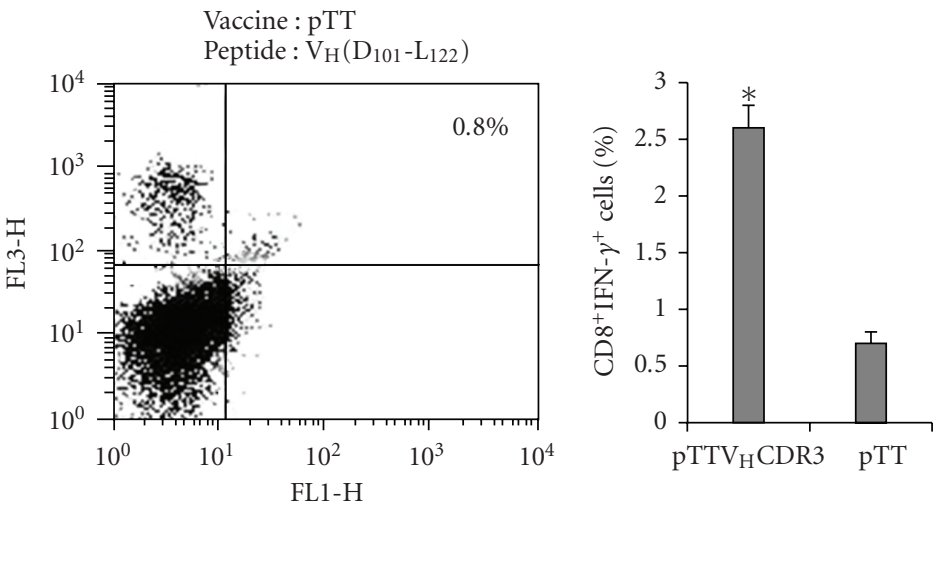

(d)

FIGURE 2: Immune responses elicited after $\mathrm{pTTV}_{\mathrm{H}} \mathrm{CDR} 3$ and pTT immunizations. Humoral immunity was assayed by ELISA for mice sera $\mathrm{V}_{\mathrm{H}}$ peptide $\left(\mathrm{D}_{101}-\mathrm{L}-{ }_{122}\right)$ reactive antibodies 3 weeks after priming (a) and 2 weeks after boosting. (b) Unimmunized mice represent the control group. Each marker indicates a value from a single mouse; group means are represented by a horizontal bar. Experimental groups (pTTV $\mathrm{H}_{\mathrm{H}} \mathrm{CDR} 3$ group, $n=7$; control groups, $n=6$ ) were compared by unpaired, two-tailed $t$-test. (c) The frequency of IFN- $\gamma$-positive CD $8^{+}$ $\mathrm{T}$ cells was assessed ex vivo by intracellular cytokine staining. Splenic lymphocytes were harvested 1 week after booster injection, stimulated with $\mathrm{V}_{\mathrm{H}}$ peptide $\left(\mathrm{D}_{101}-\mathrm{L}-{ }_{122}\right)$, and assayed for IFN- $\gamma$ production on gated T lymphocytes. Representative flow cytometric plots from pooled mice ( 3 animals/experimental groups) splenocytes are shown. Numbers in FACS plots refer to CD8 ${ }^{+}$IFN- $\gamma^{+}$cells as a percentage of the total T cells population. (d) Data were pooled from two identical independent experiments to indicate the mean percentage of CD8 ${ }^{+} \mathrm{T}$ cells producing IFN- $\gamma$ in response to $\mathrm{V}_{\mathrm{H}}$ peptide. An $X^{2}$ test for the comparison of the two proportions, expressed as a percentage, was performed. Error bars: SEM. ${ }^{(*)}$ denotes a statistically significant value $(P<.0001)$.

epitope, $\mathrm{C} 3 \mathrm{H} / \mathrm{HeN}$ mice $(n=3)$ were vaccinated with the same DNA dose and regimen. Splenic lymphocytes were harvested 1 week after booster injection and processed for their ability to induce $\mathrm{V}_{\mathrm{H}}$ peptide $\left(\mathrm{D}_{101}-\mathrm{L}_{122}\right)$ positive IFN$\gamma$-producing $\mathrm{T}$ cells responses. Flow cytometry analyses in Figure 2 showed the percentage of $\mathrm{CD}^{+} \mathrm{T}$ cells producing IFN- $\gamma$. Splenocytes isolated from $\mathrm{pTTV}_{\mathrm{H}} \mathrm{CDR} 3$ vaccinated mice generated a significantly higher frequency of IFN- $\gamma$ positive $\mathrm{CD} 8^{+} \mathrm{T}$ cell precursors compared to mice vaccinated with the pTT control vaccine $(P<.0001)$. A graphical representation of the number of $\mathrm{V}_{\mathrm{H}}$ peptide $\left(\mathrm{D}_{101}-\mathrm{L}_{122}\right)$ - positive $\mathrm{CD}^{+} \mathrm{T}$ cells is depicted in Figures 2(c) and 2(d). Thus, our data suggest that vaccination with $\mathrm{pTTV}_{\mathrm{H}} \mathrm{CDR} 3$ induces priming of $\mathrm{CD} 8^{+} \mathrm{T}$ lymphocytes.

3.4. Prophylactic and Therapeutic Experiments. To address the protective tumor immunity of $\mathrm{pTTV}_{\mathrm{H}} \mathrm{CDR} 3 \mathrm{DNA}$ vaccine, we performed prophylactic vaccination experiments. The details of the immunization protocol and the tumor challenge are described in Figure 1(b). The immunization regimen was previously developed for another CDR3-based vaccine formulation and proved to be efficacious [22]. 


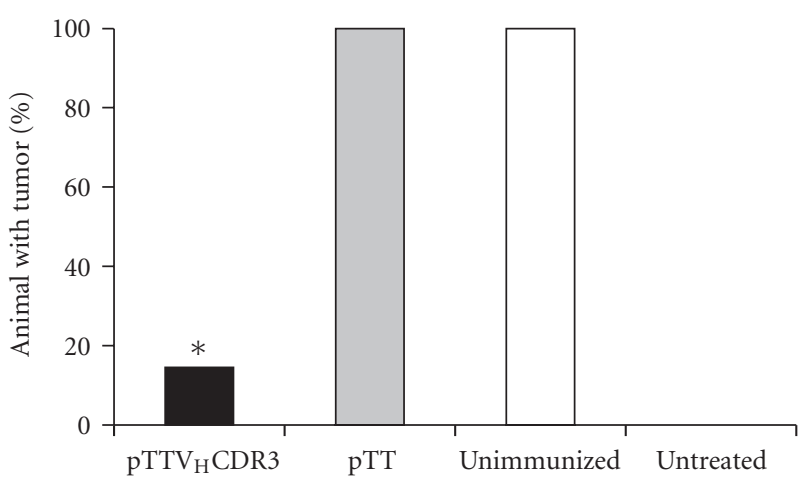

(a)

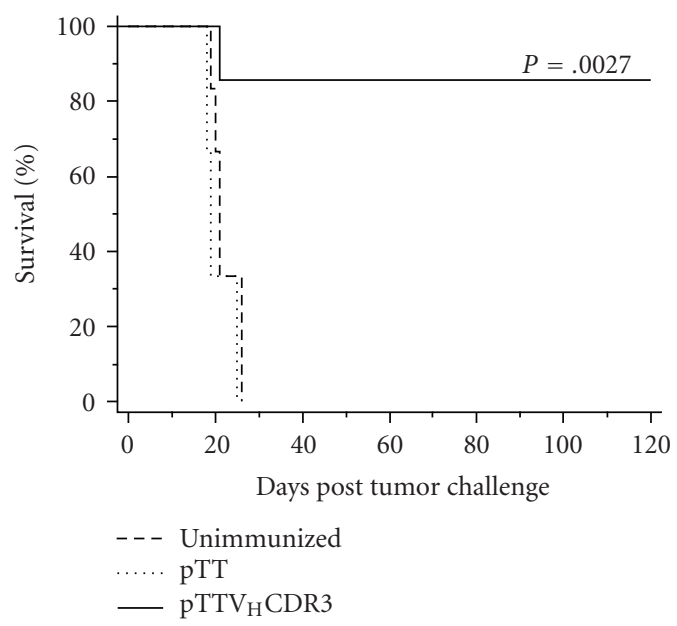

(b)

Figure 3: In vivo antitumor effects generated by immunization with pTTV $_{\mathrm{H}} \mathrm{CDR} 3$ vaccine. (a) Tumor resistance. ${ }^{(*)}$ denotes a statistically significant value $(P<.001)$ by $X^{2}$ analysis when comparing the pTTV $\mathrm{H}_{\mathrm{H}} \mathrm{CDR}$ group $(n=7)$ to all other groups $(n=6)$. (b) Representative long-term tumor-free survival. Survival analyses were performed using the Kaplan-Meier method and the log-rank test $(P=.0027)$.

Two weeks after the last DNA electrotransfer, animals (pTTV ${ }_{\mathrm{H}} \mathrm{CDR} 3$ group, $n=7$; control groups, $n=6$ ) were challenged intraperitoneally (i.p.) with a lethal dose of 38C13 tumor B-cells. The development of i.p. lymphoma was monitored for each mouse and the protective efficacy of fusion vaccine was evaluated in terms of survival of mice over the next 120 days. Immunization with the pTTV $_{H}$ CDR3 DNA significantly impacted tumor growth and ensured longterm tumor-free survival of about $85 \%$ of treated mice $(P=$ .0027) (Figures 3(a) and 3(b)). Cohorts vaccinated with the pTT control vaccine or phosphate buffer showed poor lymphoma resistance, with all mice showing median survival time of 19 days.

The potent prophylactic antitumor effect prompted us to assess the therapeutic vaccination against established 38C13 tumor. Therefore, based on our previous data [22] and recent findings (manuscript in preparation), we evaluated the combined effect of $V_{H} C D R 3$ and $V_{L} C D R 3$ peptides fused to $\mathrm{TT}_{933-1126}$ FrC portion in a therapeutic setting. Four days after challenging $\mathrm{C} 3 \mathrm{H} / \mathrm{HeN}$ mice $(6$ mice/experimental group) with a tumorigenic dose of $38 \mathrm{C} 13$ cells, DNA electrotransfer with TTV $_{\mathrm{H}} \mathrm{CDR}_{3} / \mathrm{pTTV}_{\mathrm{L}} \mathrm{CDR} 3$ or with $\mathrm{pTT}$ was performed and repeated 11 days later. Even though the timing of tumor onset was similar for the plasmids injected mice and the control mice, at days 18-22 postchallenge all untreated and pTT control mice succumbed. DNA vaccination with $\mathrm{pTTV} \mathrm{H}_{\mathrm{H}} \mathrm{CDR} 3 / \mathrm{pTTV} \mathrm{T}_{\mathrm{L}} \mathrm{CDR} 3$ resulted in a trend toward a prolongation of life span through day 35 posttumor challenge, although the delay in death rate was not statically significant (Table 2).

\section{Discussion}

We have previously developed a DNA-based vaccine containing the 8-mer H-2KK "anchor modified" YEGYFDYI $109-116$ epitope of $\mathrm{V}_{\mathrm{H}} \mathrm{CDR} 3$ sequence of the murine 38C13 B-cell lymphoma. The $\mathrm{V}_{\mathrm{H}} \mathrm{CDR} 3$ epitope has been shown to be protective in combination with the $\mathrm{V}_{\mathrm{L}} \mathrm{CDR} 3$ peptide in a murine tumor protection experiment [22].

In the current study, we aim to gain insights into the enhancement of the effectiveness of the $\mathrm{V}_{\mathrm{H}} \mathrm{CDR} 3$-based DNA vaccine in terms of specific immune responses and tumor protection in mice.

Induction of potent immune responses against selftumor antigens is not an easy task. Fusion of the antigen with foreign universal $\mathrm{T}_{\mathrm{H}}$ epitopes (such as tetanus toxoid epitopes) has been shown to brake the tolerance to self-antigen and render a weak tumor antigen more immunogenic.

Engagement of $\mathrm{CD}^{+} \mathrm{T}_{\mathrm{H}}$ cells has been shown to play a major role in linking and coordinating innate and adaptive immune responses $[4,23]$.

Thus, a DNA fusion vaccine was generated following fusion of a sequence derived from TTFrC to the $\mathrm{V}_{\mathrm{H}} \mathrm{CDR} 3_{109-116}$ epitope to help immune responses against the tumor antigen. Vaccine efficacy was assayed in a highly aggressive and weakly immunogenic murine model of B-cell lymphoma.

We demonstrated that the fusion DNA vaccine pTTV $_{\mathrm{H} C D R 3}$ was able to induce detectable levels of antibodies against the peptide encompassing the $\mathrm{V}_{\mathrm{H}} \mathrm{CDR} 3$ sequence. Humoral immune response could not be achieved by first plasmid electrotransfer suggesting that boosting is critical for antibody induction for this antigen system.

Furthermore, plasmid-driven $\mathrm{TTV}_{\mathrm{H}} \mathrm{CDR} 3$ immunization resulted in the induction of significantly higher frequency of IFN- $\boldsymbol{\gamma}$-producing $\mathrm{CD}^{+} \mathrm{T}$ cell precursors as compared to control group.

Prophylactic vaccination with $\mathrm{pTTV}_{\mathrm{H}} \mathrm{CDR} 3$ DNA vaccine through the intramuscular route in combination with electroporation strongly affected the onset of highly aggressive 38C13 B-cell lymphoma. Inhibition of lymphoma growth led to significant and long-lasting protection from tumor in syngeneic mice with about $85 \%$ surviving, compared to naïve animals or those given the pTT control vaccine. This study demonstrates that fusion of exogenous protein to tumor-specific epitope converted an ineffective 
TABLE 2: Therapeutic vaccination induces life span prolongation.

\begin{tabular}{|c|c|c|c|c|c|c|}
\hline \multirow{3}{*}{ Mice group } & \multirow{3}{*}{ Vaccine formulation } & \multirow{2}{*}{\multicolumn{3}{|c|}{$\begin{array}{c}\text { Survival \% } \\
\text { (n./tot) }\end{array}$}} & \multicolumn{2}{|c|}{ Log-rank $P$-values versus } \\
\hline & & & & & Groun $\mathrm{C}$ & Groun B \\
\hline & & Day 15 & Day 22 & Day 28 & Group & D D \\
\hline A & $\mathrm{pTTV}_{\mathrm{H}} \mathrm{CDR} 3 / \mathrm{pTTV}_{\mathrm{L}} \mathrm{CDR} 3$ & $\begin{array}{l}100 \\
(6 / 6)\end{array}$ & $\begin{array}{c}50 \\
(3 / 6)\end{array}$ & $\begin{array}{c}50 \\
(3 / 6)\end{array}$ & 0.083 & 0.115 \\
\hline B & pTT & $\begin{array}{l}100 \\
(6 / 6)\end{array}$ & $\begin{array}{c}0 \\
(0 / 6) \\
\end{array}$ & & 0.408 & - \\
\hline $\mathrm{C}$ & Unimmunized & $\begin{array}{c}80 \\
(4 / 5)\end{array}$ & $\begin{array}{c}0 \\
(0 / 5)\end{array}$ & & - & - \\
\hline
\end{tabular}

vaccine, namely, $\mathrm{pV}_{\mathrm{H}}$ [22], into one with considerable activity.

The potent prophylactic antitumor effect prompted us to assess the tumor immunity in a therapeutic setting, which is more clinically relevant. Preliminary data obtained by using this DNA platform strategy provide proof of principle for the treatment of already established tumor in our model. Further enhancement of the potency of CDR3-based DNA vaccines is necessary in a therapeutic scenario; experiments testing new combinations of other crucial cytokines are under evaluation.

Attempts to identify the mechanism of Id-induced antitumor immunity to malignant B-cells have yielded variable results. Despite results from early clinical trials with Id vaccines suggest that both humoral and cellular immune responses may be independently associated with tumor regression and improved progression-free survival [38-42], the relative importance of the antibody and cell mediated immune response is still uncertain. Experiments are currently ongoing to explore the relative role of cellular versus humoral immunity for vaccine efficacy in our system.

The functional insertion of microbial sequence within the DNA vaccine was aimed to stimulate $\mathrm{CD} 4^{+} \mathrm{T}$ cell help that is critical for inducing and maintaining an effective CTL response $[23,43]$. Deeper analyses are needed to explore the role, if any, of $\mathrm{V}_{\mathrm{H}} \mathrm{CDR} 3$ peptide-specific $\mathrm{CD} 8^{+} \mathrm{T}$ cells precursors in the generation of immune responses via $\mathrm{CD} 4^{+} \mathrm{T}$ cellmediated mechanisms. The involvement of $\mathrm{CD}^{+}{ }^{+} \mathrm{T}$ helper lymphocytes at the effector phase of anti-tumor responses is coherent with $\mathrm{T}_{\mathrm{H}}$ cell-dependent "DCs licensing" [44] required for optimal vaccine efficacy, in the absence of MHC class II molecules expression by tumor cells $[28,45]$. Licensed DCs presenting peptides from both TTFrC portion and tumor antigen can be able to activate the large repertoire of anti-TTFrC $\mathrm{CD}^{+} \mathrm{T}$ cells. Hence, by ligand-receptor pairs interactions, "DCs licensing" mechanism supports priming and boosting of the weak tumor-derived peptides response [4].

Lastly, employing electrotransfer for the delivery of a DNA vaccine should improve the availability of the antigen, since EP increases and prolongs protein expression level and also results in recruitments of infiltrating inflammatory cells to the administration site [6].

\section{Conclusions}

This study demonstrates that fusion of exogenous protein to tumor-specific epitope converted an ineffective vaccine into one with considerable activity. Immune responses recruited by CDR3-based DNA fusion vaccine involve anti-Id antibody production and suggest the possible contribution of $\mathrm{CD} 8^{+} \mathrm{T}$ lymphocytes.

A vaccination protocol consisting of a naked DNA priming and boosting is attractive by virtue of ease and less time-consuming production. Furthermore, safety is also achieved since adverse immune response can be avoided (i.e., immunity generated against some viral vectors).

The CDR3-based DNA fusion vaccines strategy may prove to be a highly useful approach against B-cell lymphoma. Optimal integration of active immunization approaches into standard therapies suggests DNA vaccination as an effective treatment to eradicate minimal residual diseases during clinical remission following standard chemotherapy in lymphoma patients.

\section{Acknowlegments}

The authors are grateful to Dr. Ivano Condò (University of Tor Vergata, Rome, Italy) for helpful discussion and critical reading of the paper. They are grateful to Dr. Gianni Pozzi (University of Siena, Italy) providing the TTFrC-expressing Streptococcus gordonii strain GP1253 and to Dr. Arya Biragyn (National Institute on Aging, Baltimore, Maryland, USA) for kind gift of $38 \mathrm{C} 13$ cell line. They are grateful to the technical staff of the Animal Facility at the "Sacro Cuore" Catholic University of Rome, Italy, for their assistance. This work was supported by MUR Grant FIRB 2006 (RBIP0695BB), by Bio-Ker S.r.l. research contract (M. Rinaldi) and by the Italian Banca delle Marche. Sandra Iurescia and Daniela Fioretti have been supported by MUR Grant FIRB 2006 (RBIP0695BB) and by Bio-Ker S.r.l. S. Iurescia and D. Fioretti contributed equally to the authorship of this work. V. M. Fazio and M. Rinaldi contributed equally as senior authors. 


\section{References}

[1] A. Jemal, R. C. Tiwari, T. Murray, et al., "Cancer statistics, 2004," CA: A Cancer Journal for Clinicians, vol. 54, no. 1, pp. 8-29, 2004.

[2] R. Houot and R. Levy, "Vaccines for lymphomas: idiotype vaccines and beyond," Blood Reviews, vol. 23, no. 3, pp. 137$142,2009$.

[3] A. Koumarianou, P. Kountourakis, and T. Economopoulos, "Vaccine strategies in the treatment of low-grade nonHodgkin lymphoma," Journal of Steroid Biochemistry and Molecular Biology, vol. 109, no. 3-5, pp. 230-232, 2008.

[4] J. Rice, C. H. Ottensmeier, and F. K. Stevenson, "DNA vaccines: precision tools for activating effective immunity against cancer," Nature Reviews Cancer, vol. 8, no. 2, pp. 108$120,2008$.

[5] M. A. Kutzler and D. B. Weiner, "DNA vaccines: ready for prime time?" Nature Reviews Genetics, vol. 9, no. 10, pp. 776$788,2008$.

[6] G. Ahlen, J. Soderholm, T. Tjelle, et al., "In vivo electroporation enhances the immunogenicity of hepatitis $C$ virus nonstructural 3/4A DNA by increased local DNA uptake, protein expression, inflammation, and infiltration of $\mathrm{CD}^{+} \mathrm{T}$ cells," Journal of Immunology, vol. 179, no. 7, pp. 4741-4753, 2007.

[7] S. A. Hurvitz and J. M. Timmerman, "Current status of therapeutic vaccines for non-Hodgkin's lymphoma," Current Opinion in Oncology, vol. 17, no. 5, pp. 432-440, 2005.

[8] S. S. Neelapu, S.-T. Lee, H. Qin, S.-C. Cha, A. F. Woo, and L. W. Kwak, "Therapeutic lymphoma vaccines: importance of T-cell immunity," Expert Review of Vaccines, vol. 5, no. 3, pp. 381394, 2006.

[9] F. Benvenuti, O. R. Burrone, and D. G. Efremov, "Antiidiotypic DNA vaccines for lymphoma immunotherapy require the presence of both variable region genes for tumor protection," Gene Therapy, vol. 7, no. 7, pp. 605-611, 2000.

[10] A. Biragyn, K. Tani, M. C. Grimm, S. Weeks, and L. W. Kwak, "Genetic fusion of chemokines to a self tumor antigen induces protective, T-cell dependent antitumor immunity," Nature Biotechnology, vol. 17, no. 3, pp. 253-258, 1999.

[11] C. A. King, M. B. Spellerberg, D. Zhu, et al., "DNA vaccines with single-chain Fv fused to fragment $\mathrm{C}$ of tetanus toxin induce protective immunity against lymphoma and myeloma," Nature Medicine, vol. 4, no. 11, pp. 1281-1286, 1998.

[12] M. B. Spellerberg, D. Zhu, A. Thompsett, C. A. King, T. J. Hamblin, and F. K. Stevenson, "DNA vaccines against lymphoma: promotion of anti-idiotypic antibody responses induced by single chain $\mathrm{Fv}$ genes by fusion to tetanus toxin fragment C," Journal of Immunology, vol. 159, no. 4, pp. 18851892, 1997.

[13] A. D. Syrengelas, T. T. Chen, and R. Levy, "DNA immunization induces protective immunity against B-cell lymphoma," Nature Medicine, vol. 2, no. 9, pp. 1038-1041, 1996.

[14] D. Zhu, J. Rice, N. Savelyeva, and F. K. Stevenson, "DNA fusion vaccines against B-cell tumors," Trends in Molecular Medicine, vol. 7, no. 12, pp. 566-572, 2001.

[15] S. Baskar, C. B. Kobrin, and L. W. Kwaka, "Autologous lymphoma vaccines induce human $\mathrm{T}$ cell responses against multiple, unique epitopes," Journal of Clinical Investigation, vol. 113, no. 10, pp. 1498-1510, 2004.

[16] M. J. Campbell, W. Carroll, S. Kon, et al., "Idiotype vaccination against murine B cell lymphoma. Humoral and cellular responses elicited by tumor-derived immunoglobulin $\mathrm{M}$ and its molecular subunits," Journal of Immunology, vol. 139, no. 8, pp. 2825-2833, 1987.

[17] L. Hansson, H. Rabbani, J. Fagerberg, A. Osterborg, and H. Mellstedt, "T-cell epitopes within the complementaritydetermining and framework regions of the tumor-derived immunoglobulin heavy chain in multiple myeloma," Blood, vol. 101, no. 12, pp. 4930-4936, 2003.

[18] A. Watanabe, E. Raz, H. Kohsaka, et al., "Induction of antibodies to a $\kappa \mathrm{V}$ region by gene immunization," Journal of Immunology, vol. 151, no. 5, pp. 2871-2876, 1993.

[19] S. Y. Lim, S. Laxmanan, G. Stuart, and S. K. Ghosh, "Anti-lymphoma immunity: relative efficacy of peptide and recombinant DNA vaccine," Cancer Detection and Prevention, vol. 25, no. 5, pp. 470-478, 2001.

[20] M. Rinaldi, F. Ria, P. Parrella, et al., "Antibodies elicited by naked DNA vaccination against the complementary-determining region 3 hypervariable region of immunoglobulin heavy chain idiotypic determinants of B-lymphoproliferative disorders specifically react with patients' tumor cells," Cancer Research, vol. 61, no. 4, pp. 1555-1562, 2001.

[21] Y. Bergman, J. Haimovich, and F. Melchers, "An IgMproducing tumor with biochemical characteristics of a small B lymphocyte," European Journal of Immunology, vol. 7, no. 8, pp. 574-579, 1977.

[22] M. Rinaldi, D. Fioretti, S. Iurescia, et al., "Anti-tumor immunity induced by CDR3-based DNA vaccination in a murine Bcell lymphoma model," Biochemical and Biophysical Research Communications, vol. 370, no. 2, pp. 279-284, 2008.

[23] E. M. Janssen, E. E. Lemmens, T. Wolfe, U. Christen, M. G. Von Herrath, and S. P. Schoenberger, "CD4 ${ }^{+} \mathrm{T}$ cells are required for secondary expansion and memory in $\mathrm{CD} 8^{+} \mathrm{T}$ lymphocytes," Nature, vol. 421, no. 6925, pp. 852-856, 2003.

[24] L. H. Lund, K. Andersson, B. Zuber, et al., "Signal sequence deletion and fusion to tetanus toxoid epitope augment antitumor immune responses to a human carcinoembryonic antigen (CEA) plasmid DNA vaccine in a murine test system," Cancer Gene Therapy, vol. 10, no. 5, pp. 365-376, 2003.

[25] J. Rice, T. Elliott, S. Buchan, and F. K. Stevenson, "DNA fusion vaccine designed to induce cytotoxic $\mathrm{T}$ cell responses against defined peptide motifs: implications for cancer vaccines," Journal of Immunology, vol. 167, no. 3, pp. 1558-1565, 2001.

[26] F. K. Stevenson, J. Rice, C. H. Ottensmeier, S. M. Thirdborough, and D. Zhu, "DNA fusion gene vaccines against cancer: from the laboratory to the clinic," Immunological Reviews, vol. 199, pp. 156-180, 2004.

[27] S. Tymciu, C. Durieux-Alexandrenne, A. Wijkhuisen, et al., "Enhancement of antibody responses in DNA vaccination using a vector encoding a universal T-helper cell epitope," DNA and Cell Biology, vol. 23, no. 6, pp. 395-402, 2004.

[28] B. B. Williams, M. Wall, R. Y. Miao, et al., "Induction of T cellmediated immunity using a c-Myb DNA vaccine in a mouse model of colon cancer," Cancer Immunology, Immunotherapy, vol. 57, no. 11, pp. 1635-1645, 2008.

[29] D. Medaglini, A. Ciabattini, M. R. Spinosa, et al., "Immunization with recombinant Streptococcus gordonii expressing tetanus toxin fragment $\mathrm{C}$ confers protection from lethal challenge in mice," Vaccine, vol. 19, no. 15-16, pp. 1931-1939, 2001.

[30] M.-P. Lefranc, C. Pommie, M. Ruiz, et al., "IMGT unique numbering for immunoglobulin and $\mathrm{T}$ cell receptor variable domains and Ig superfamily V-like domains," Developmental and Comparative Immunology, vol. 27, no. 1, pp. 55-77, 2003. 
[31] J. M. McMahon, E. Signori, K. E. Wells, V. M. Fazio, and D. J. Wells, "Optimisation of electrotransfer of plasmid into skeletal muscle by pretreatment with hyaluronidaseincreased expression with reduced muscle damage," Gene Therapy, vol. 8, no. 16, pp. 1264-1270, 2001.

[32] H.-G. Rammensee, J. Bachmann, N. P. N. Emmerich, O. A. Bachor, and S. Stevanovic, "SYFPEITHI: database for MHC ligands and peptide motifs," Immunogenetics, vol. 50, no. 3-4, pp. 213-219, 1999.

[33] P. Panina-Bordignon, A. Tan, A. Termijtelen, S. Demotz, G. Corradin, and A. Lanzavecchia, "Universally immunogenic T cell epitopes: promiscuous binding to human MHC class II and promiscuous recognition by T cells," European Journal of Immunology, vol. 19, no. 12, pp. 2237-2242, 1989.

[34] S. Demotz, C. Barbey, G. Corradin, A. Amoroso, and A. Lanzavecchia, "The set of naturally processed peptides displayed by DR molecules is tuned by polymorphism of residue 86 ," European Journal of Immunology, vol. 23, no. 2, pp. 425-432, 1993.

[35] E. A. James, J. Bui, D. Berger, L. Huston, M. Roti, and W. W. Kwok, "Tetramer-guided epitope mapping reveals broad, individualized repertoires of tetanus toxin-specific $\mathrm{CD}^{+} \mathrm{T}$ cells and suggests HLA-based differences in epitope recognition," International Immunology, vol. 19, no. 11, pp. 1291-1301, 2007.

[36] W. Chen and J. McCluskey, "Immunodominance and immunodomination: critical factors in developing effective $\mathrm{CD}^{+} \mathrm{T}$ cell-based cancer vaccines," Advances in Cancer Research, vol. 95, pp. 203-247, 2006.

[37] I. Hakim, S. Levy, and R. Levy, "A nine-amino acid peptide from IL-1beta augments antitumor immune responses induced by protein and DNA vaccines," Journal of Immunology, vol. 157, no. 12, pp. 5503-5511, 1996.

[38] F. J. Hsu, C. B. Caspar, D. Czerwinski, et al., "Tumor-specific idiotype vaccines in the treatment of patients with B- cell lymphoma-long-term results of a clinical trial," Blood, vol. 89, no. 9, pp. 3129-3135, 1997.

[39] F. J. Hsu, C. Benike, F. Fagnoni, et al., "Vaccination of patients with B-cell lymphoma using autologous antigenpulsed dendritic cells," Nature Medicine, vol. 2, no. 1, pp. 5258, 1996.

[40] L. W. Kwak, M. J. Campbell, D. K. Czerwinski, S. Hart, R. A. Miller, and R. Levy, "Induction of immune responses in patients with B-cell lymphoma against the surfaceimmunoglobulin idiotype expressed by their tumors," The New England Journal of Medicine, vol. 327, no. 17, pp. 12091215, 1992.

[41] S. S. Neelapu, S. Baskar, B. L. Gause, et al., "Human autologous tumor-specific T-cell responses induced by liposomal delivery of a lymphoma antigen," Clinical Cancer Research, vol. 10, no. 24, pp. 8309-8317, 2004.

[42] J. M. Timmerman, D. K. Czerwinski, T. A. Davis, et al., "Idiotype-pulsed dendritic cell vaccination for B-cell lymphoma: clinical and immune responses in 35 patients," Blood, vol. 99, no. 5, pp. 1517-1526, 2002.

[43] S. Zhang, H. Zhang, and J. Zhao, "The role of CD4 T cell help for CD8 CTL activation," Biochemical and Biophysical Research Communications, vol. 384, no. 4, pp. 405-408, 2009.

[44] C. M. Smith, N. S. Wilson, J. Waithman, et al., "Cognate CD4+ $\mathrm{T}$ cell licensing of dendritic cells in $\mathrm{CD} 8^{+} \mathrm{T}$ cell immunity," Nature Immunology, vol. 5, no. 11, pp. 1143-1148, 2004.
[45] W. W. Leitner, M. C. Baker, T. L. Berenberg, M. C. Lu, J. P. Yannie, and M. C. Udey, "Enhancement of DNA tumor vaccine efficacy by gene gun mediated codelivery of threshold amounts of plasmid-encoded helper antigen," Blood, vol. 113, no. 1, pp. 37-45, 2009. 


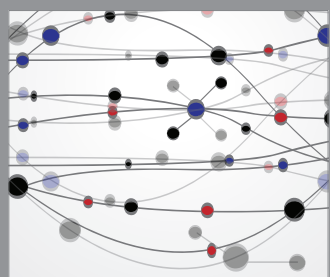

The Scientific World Journal
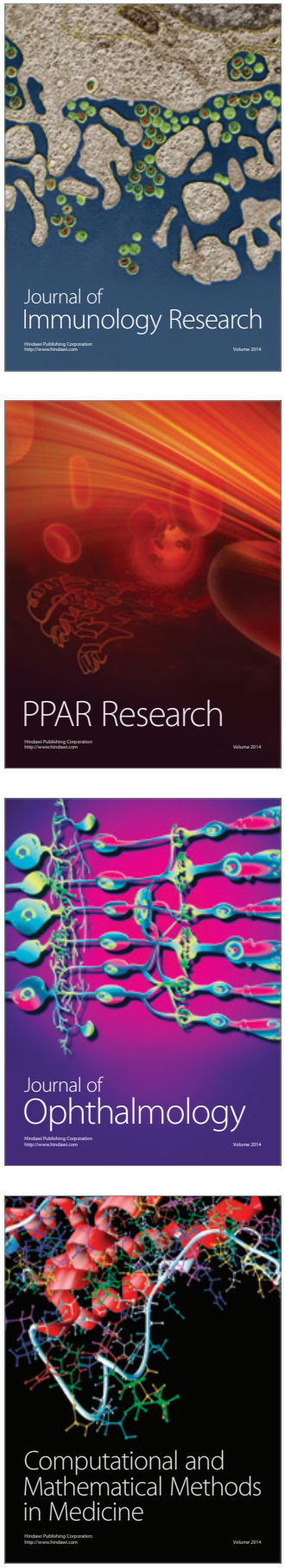

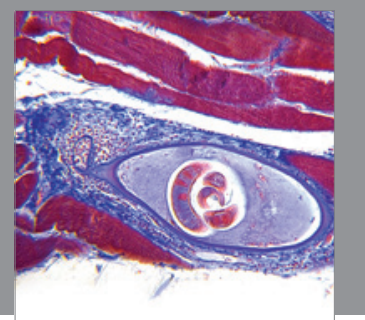

Gastroenterology

Research and Practice
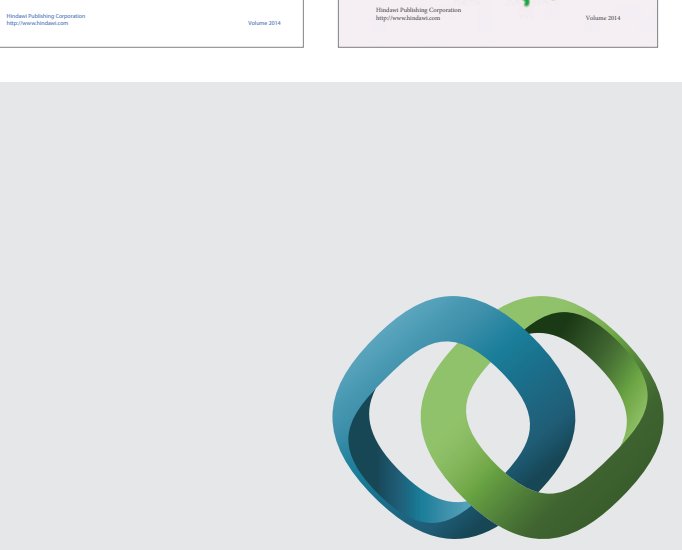

\section{Hindawi}

Submit your manuscripts at

http://www.hindawi.com
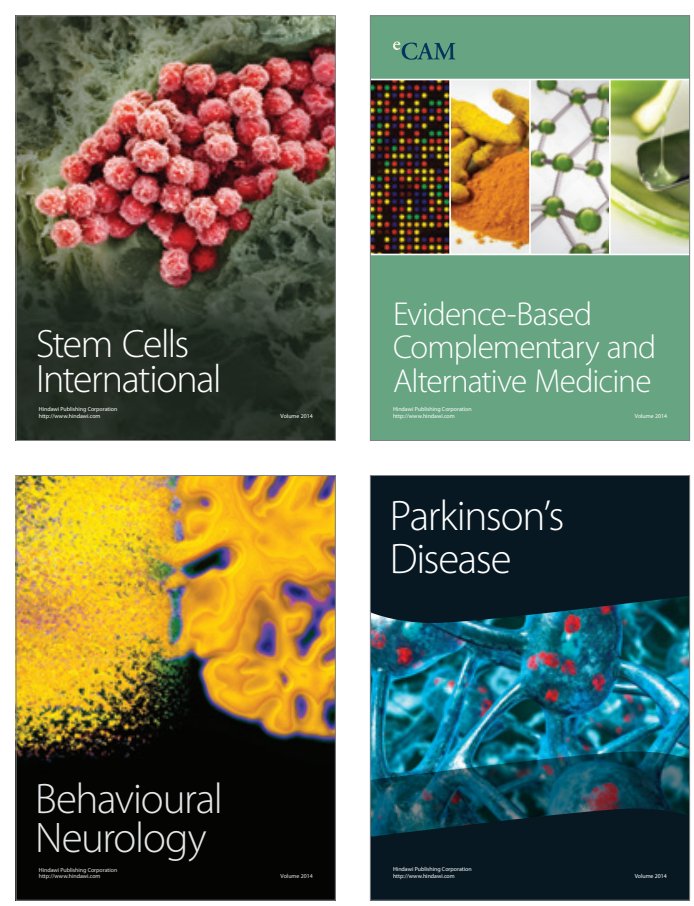

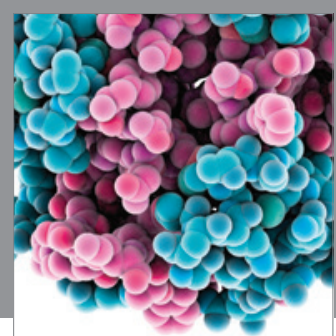

Journal of
Diabetes Research

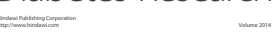

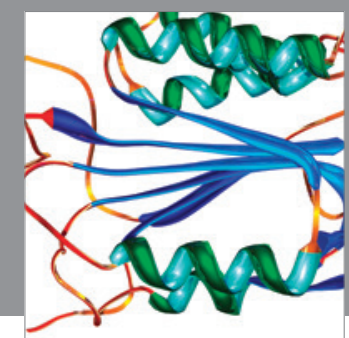

Disease Markers
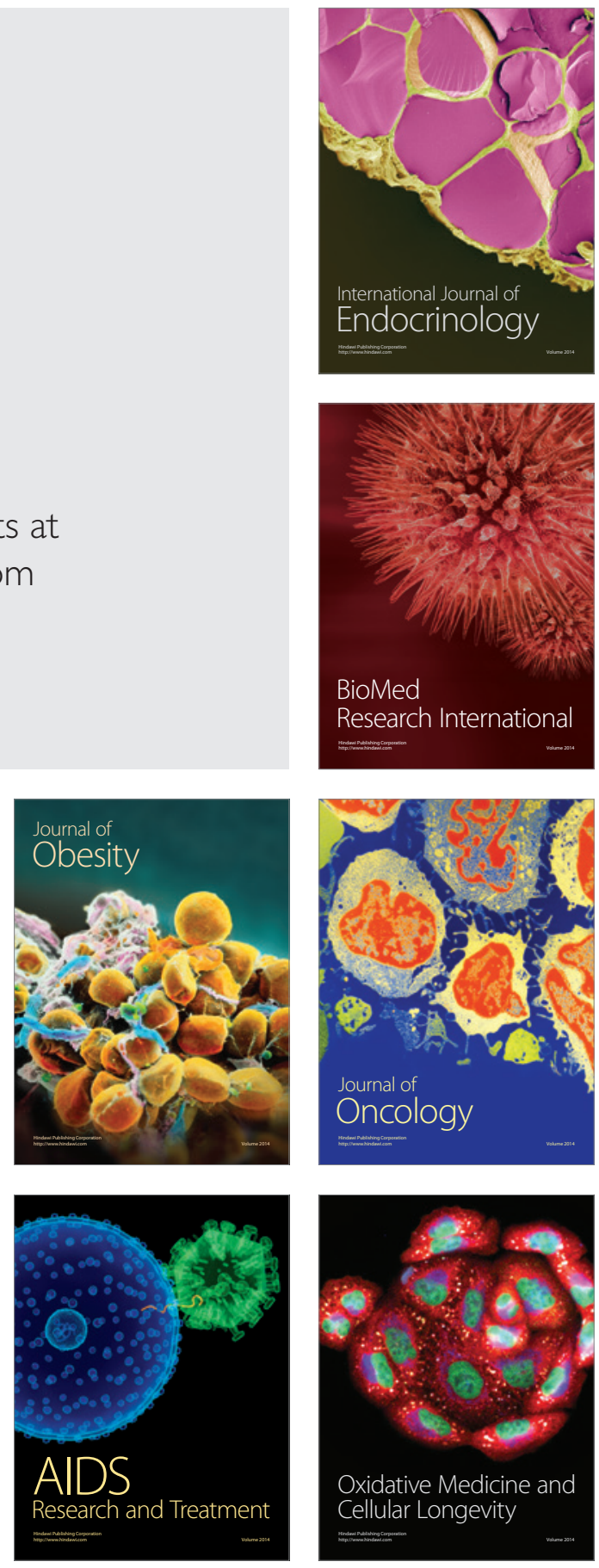